\title{
Hepatoblastoma Associated with Trisomy 18
}

\author{
Leonardo I. Valentin ${ }^{1} \quad$ Luis Perez $^{2} \quad$ Prakash Masand $^{1}$ \\ ${ }^{1}$ Department of Radiology, Texas Children's Hospital, Baylor College of \\ Medicine, Houston, Texas, United States \\ 2 Department of Radiology, Mount Sinai St. Luke's-Roosevelt Hospital \\ Center, New York, United States \\ Address for correspondence Leonardo I. Valentin, MD, Department of \\ Radiology, Texas Children's Hospital, Baylor College of Medicine, One \\ Baylor Plaza-BCM360, Houston, Texas 77030, United States \\ (e-mail: Ivalenti@bcm.edu).
}

J Pediatr Genet 2015;4:204-206.
Abstract
Keywords
- hepatoblastoma
- magnetic resonance imaging
- child
- trisomy 18

Very few reports exist in the literature regarding a possible association between trisomy 18 patients and the incidence of hepatoblastoma. Fewer reports exist on patients with multifocal hepatoblastoma. We reviewed our institutional database for the past 10 years and found three cases with this possible association to the tumor.

\section{Introduction}

Trisomy 18, also known as Edwards syndrome, is the second most common trisomic genetic disorder after Down syndrome. ${ }^{1}$ Like Down syndrome, the risk for trisomy 18 increases with increased maternal age. Though there is considerable phenotypic variability among patients, only 5 to $10 \%$ survive past the first year of life. ${ }^{2}$ Many abnormalities are associated with trisomy 18 and include cardiac (i.e., ventriculoseptal defect [VSD], atrial septal defect [ASD], patent ductus arteriosus [PDA]), neurologic, gastrointestinal, and renal. Among the defects, cardiac anomalies are present in more than $90 \%$ of the patients, whereas other structural malformations such as radial hypoplasia, microphthalmia, omphalocele, and orofacial clefts occur less frequently $(5-25 \%){ }^{3}$ In the pediatric population, hepatoblastoma is the most common malignant neoplasm derived from mesenchymal and epithelial cells. It has also been associated with low birth weight and prematurity. Because of improved medical care and increased survival of lowbirth-weight newborns, the incidence of hepatoblastoma is on the rise. This tumor has also a reported increased incidence in males by a ratio of to $2: 1{ }^{4}$

These patients characteristically present with an enlarging, painless mass in the abdomen. Most patients have an abnormally elevated $\alpha$-fetoprotein (AFP), which serves as a marker to monitor therapy and disease recurrence. ${ }^{5}$ Another useful laboratory marker is the human chorionic gonadotropin-in which patients with elevated levels may present with precocious puberty. Metastatic disease is more commonly found in the lungs and affects 10 to $20 \%$ of the cases. Increased AFP levels $(\geq 1,000,000 \mathrm{ng} /$ $\mathrm{mL}$ ) are usually found in those cases. Overall survival rate for patients with hepatoblastoma in the general population has improved and often reported as 65 to $70 \%{ }^{6}$

Although hepatoblastoma has been associated with other genetic abnormalities, very little is known about its possible association with trisomy 18 given limited data and confounding factors. Approximately 10 biopsy-proven cases exist in the medical literature and only three with multifocal involvement. We report a case of a child with trisomy 18 and multifocal hepatoblastoma in addition to two additional cases from our institutional database.

\section{Case Report}

We report the case of a 1-year-old girl diagnosed with trisomy 18 . She was undergoing a screening abdominal ultrasound for Wilms tumor surveillance, when an hepatic mass was identified. The mass appeared well-circumscribed, predominantly isoechoic with a hypoechoic rim and internal vascularity (-Fig. 1). The patient also had history of a neck hemangioma that was surgically resected. Given this prior history, the diagnosis of liver hemangioma was considered. However, given the limitations of sonography to discern between a received

February 8, 2015

accepted after revision

April 8, 2015

published online

October 19, 2015
Copyright $\odot 2015$ by Georg Thieme

Verlag KG, Stuttgart · New York
DOI http://dx.doi.org/ 10.1055/s-0035-1565265. ISSN 2146-4596. 


\section{A}
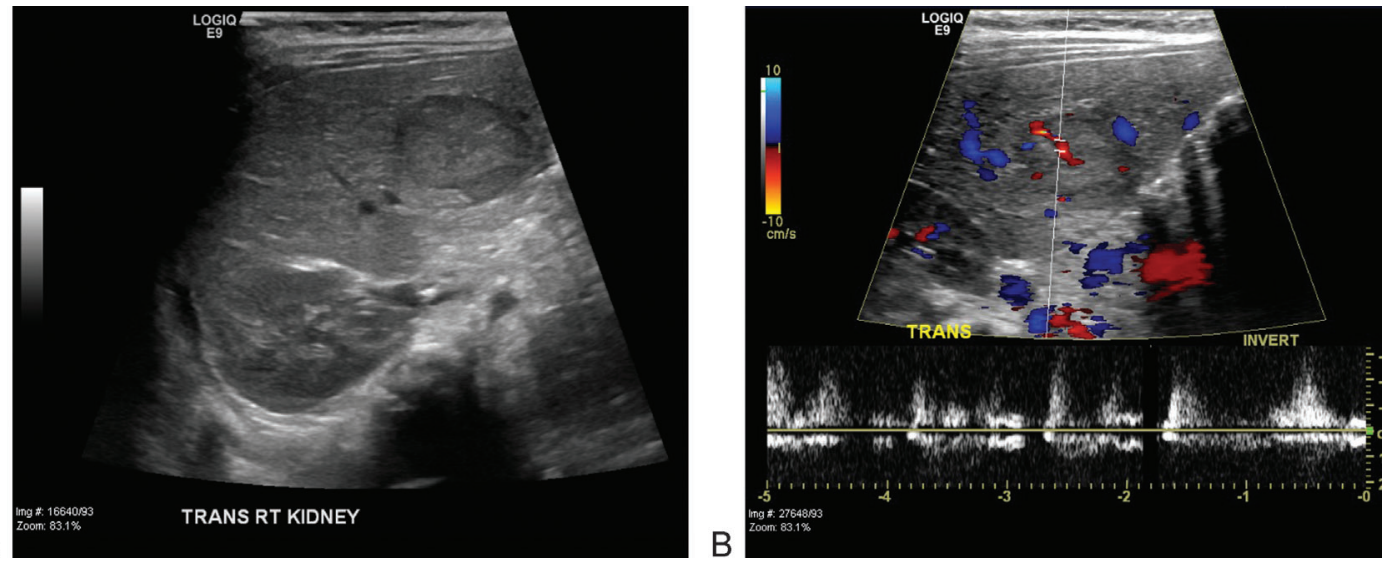

Fig. 1 Ultrasound images of the liver show a predominantly isoechoic mass in the right liver lobe (A) with evidence of internal vascularity on color Doppler (B).

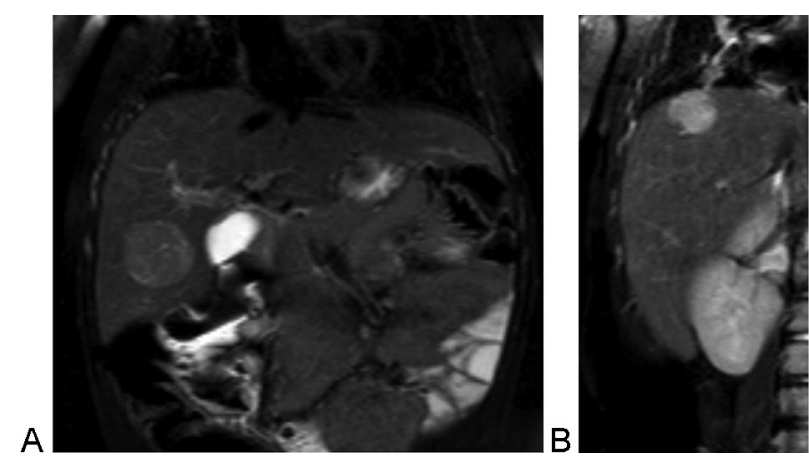

Fig. 2 Coronal T2-weighted images of the liver show previously noted mass with slightly increased signal intensity (A). An additional lesion, slightly brighter on T2-weigthed imaging, was noted near the hepatic dome (B).

malignant or benign process, a dedicated magnetic resonance imaging (MRI) of the liver was recommended. Contrastenhanced (Eovist) MRI of the liver revealed an additional lesion (for a total of two lesions) (-Fig. 2). Both lesions were hypointense on T1-weighted images and slightly hyperin-

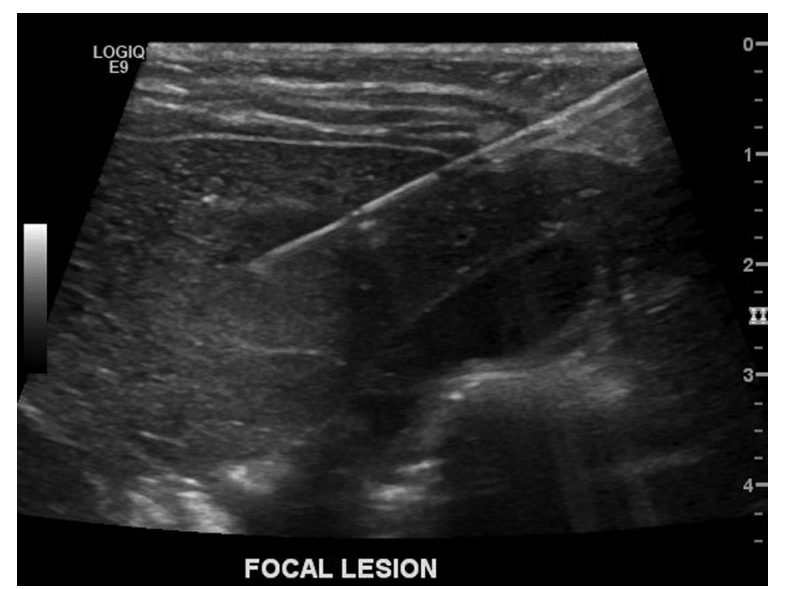

Fig. 4 Right hepatic lobe lesion, ultrasound-guided biopsy-fine needle aspiration (FNA)-with 20 gauge Chiba needle.

tense on T2-weighted images. The second lesion that was only identified with MRI had relatively similar characteristics, although brighter T2 signal. AFP levels were $57.1 \mathrm{ng} / \mathrm{mL}-$ which was only mildly elevated (reference range $<12 \mathrm{ng} / \mathrm{mL}$ ) and human chorionic gonadotropin (hCG) levels were normal

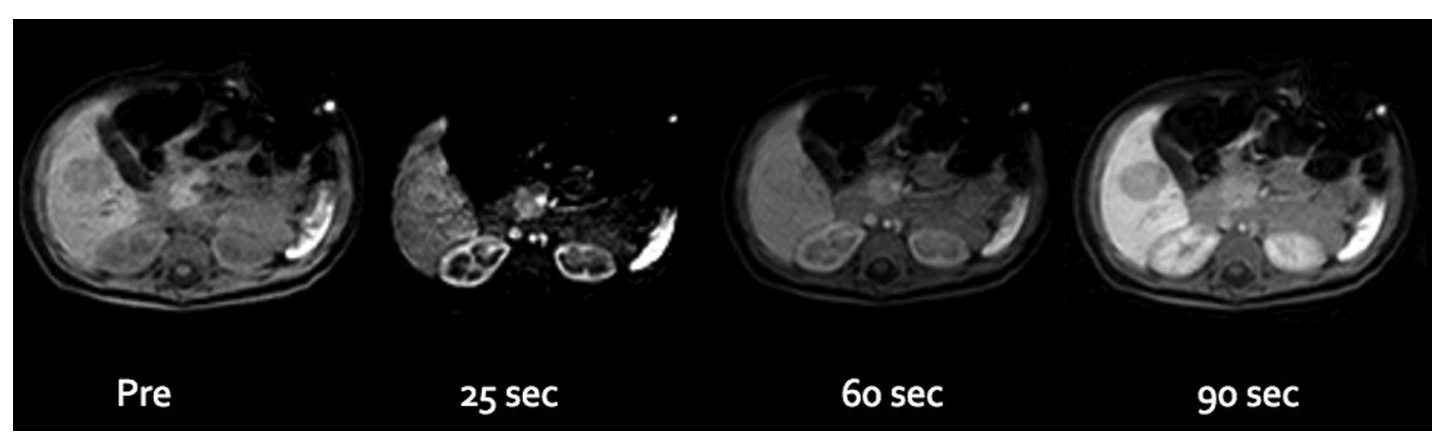

Fig. 3 Postcontrast (Eovist), thrive images were obtained with pre, 25-, 60-, and 90-second delay. The hypointense mass on precontrast imaging showed some heterogeneous enhancement at 25 -second, subsequent equilibration at 60 -second, and washout at 90 -second delayed imaging in relation to the liver parenchyma. 
Table 1 Summary of characteristics in patients with trisomy 18 and hepatoblastoma at Texas Children's Hospital, Baylor College of Medicine (2004-2014)

\begin{tabular}{|l|l|l|l|l|l|}
\hline Age at diagnosis & Sex & Surgical treatment & AFP $(\mathbf{n g} / \mathrm{mL})$ & Biopsy & Alive \\
\hline $1 \mathrm{y}$ & Female & $\boldsymbol{5}$ & 52 & $\boldsymbol{V}$ & No biopsy available \\
\hline $11 \mathrm{mo}$ & Female & $\begin{array}{l}\text { Surgical intervention } \\
\text { deferred by family }\end{array}$ & 9,160 & $\begin{array}{l}\text { Deceased from } \\
\text { cardiac complications }\end{array}$ \\
\hline $4 \mathrm{y}$ & Female & $\boldsymbol{V}$ & $841^{\mathrm{a}}$ & $\boldsymbol{V}^{\mathrm{b}}$ & $\boldsymbol{V}$ \\
\hline
\end{tabular}

Abbreviation: AFP, $\alpha$-fetoprotein.

${ }^{a}$ AFP-at 5 days postresection.

${ }^{\mathrm{b}}$ Biopsy not performed at our institution.

( $<2 \mathrm{mIU} / \mathrm{mL}$ ). The pattern of enhancement was heterogeneous with subsequent washout on delayed images ( - Fig. 3 ). The pattern was not typical for a hemangioma and biopsy was therefore recommended. Percutaneous biopsy of the lesion first identified on ultrasound was performed by the pediatric interventional radiology team, revealing the diagnosis of hepatoblastoma (-Fig. 4). Surgical resection of both lesions proceeded. Multifocal hepatoblastoma was then confirmed by pathologic analysis revealing well-differentiated fetal predominant subtype with small foci of pleomorphic fetal component. Presence of pure fetal histology is associated with the best prognosis compared with all other histologic subtypes. ${ }^{7}$ Low nuclear-cytoplasmic ratio, close resemblance of the normal fetal liver, and low mitotic figures within the fetal cells make this a favorable subtype. ${ }^{8}$ After resection AFP levels decreased to $15.4 \mathrm{ng} / \mathrm{mL}$ (before treatment it had decreased to $39.7 \mathrm{ng} / \mathrm{mL}$ ). Given the pleomorphic fetal component of her tumor with higher mitotic index, the patient required adjuvant chemotherapy. Given her low risk status, two cycles of cisplatin, 5-fluorouracil (5-FU), and vincristine (VCR) were recommended.

\section{Discussion}

A screening abdominal ultrasound and a high suspicion for intraabdominal tumors such as Wilms tumor and hepatoblastoma might prove to be beneficial for patients with trisomy 18 who survive past the first year of life. Nonionizing radiation and minimal patient discomfort make ultrasound an excellent modality for this type of assessment, in which early detection might avoid the need for transplantation and the costs and risks associated with this intervention, hospitalization, and subsequent immunosuppression regimen. Successful surgical resection of two relatively small lesions, as opposed to transplantation, was performed in our patient, illustrating the benefit of early detection. In two previously reported cases, two female patients ( 2 and 3 years old) underwent surgical resection of fetal-type dominant hepatoblastoma. On follow-up, the patients had no evidence of recurrence at 3 and 4 years of age, respectively. ${ }^{4}$ It has been reported that this treatment approach can be considered in patients with trisomy 18 and pretreatment extent of disease (PRETEXT) stage 1 tumors. ${ }^{1}$ Our patient in this case had a PRETEXT stage of 2, and treated with surgical resection and adjuvant chemotherapy, as previously mentioned. Another patient being followed up at our institution-who was diagnosed and surgically treated without adjuvant chemotherapy at the age of 4-has remained free from recurrence for 10 years (-Table 1). In that same case, AFP level monitoring was stopped after being normal for 4 years after surgery.

At least 12 cases have been reported in medical literature of patients with trisomy 18 linked to hepatoblastoma, with most of them being females, due to the syndrome's increased preponderance in female patients. Patients with this condition tend to have intrauterine growth restriction (IUGR) and low birth weight, which has been reported as an important risk factor of hepatoblastoma. Therefore, it is important to interpret our findings of correlation in light of available data and not assume causation until further studies are conducted to determine whether association is related to the chromosomal abnormality characteristic of Edwards syndrome or secondary to already known risk factors. More data are needed to determine whether there is a real association between hepatoblastoma and trisomy 18 , and if so, we must evaluate how different is this type of hepatoblastoma. This information could help determine the mainstay of treatment in these unique cases and even open us to new knowledge regarding genetic and molecular mechanisms leading to hepatoblastoma in the general pediatric population.

\section{References}

1 Tan ZH, Lai A, Chen CK, Chang KT, Tan AM. Association of trisomy 18 with hepatoblastoma and its implications. Eur J Pediatr 2014; 173(12):1595-1598

2 Uekusa S, Sugito K, Kawashima H, et al. Successful treatment for hepatoblastoma in a 1-year-old boy with trisomy 18 . Pediatr Int 2012;54(3):428-430

3 Cereda A, Carey JC. The trisomy 18 syndrome. Orphanet J Rare Dis 2012;7(1):81

4 Kitanovski L, Ovcak Z, Jazbec J. Multifocal hepatoblastoma in a 6month-old girl with trisomy 18: a case report. J Med Case Reports 2009;3:8319

5 Adeyiga AO, Lee EY, Eisenberg RL. Focal hepatic masses in pediatric patients. AJR Am J Roentgenol 2012;199(4):W422-440

6 Chung EM, Lattin GE Jr, Cube R, et al. From the archives of the AFIP: Pediatric liver masses: radiologic-pathologic correlation. Part 2. Malignant tumors. Radiographics 2011;31(2):483-507

7 Malogolowkin MH, Katzenstein HM, Meyers RL, et al. Complete surgical resection is curative for children with hepatoblastoma with pure fetal histology: a report from the Children's Oncology Group. J Clin Oncol 2011;29(24):3301-3306

8 Rougemont A-L, McLin VA, Toso C, Wildhaber BE. Adult hepatoblastoma: learning from children. J Hepatol 2012;56(6):1392-1403 